\title{
Possible impacts of climate change on freezing rain in south-central Canada using downscaled future climate scenarios
}

\author{
C. S. Cheng, H. Auld, G. Li, J. Klaassen, and Q. Li \\ Meteorological Service of Canada Branch, Environment Canada, 4905 Dufferin Street, Toronto, Ontario, M3H 5T4, Canada
}

Received: 17 July 2006 - Revised: 21 December 2006 - Accepted: 21 December 2006 - Published: 22 January 2007

\begin{abstract}
Freezing rain is a major atmospheric hazard in mid-latitude nations of the globe. Among all Canadian hydrometeorological hazards, freezing rain is associated with the highest damage costs per event. Using synoptic weather typing to identify the occurrence of freezing rain events, this study estimates changes in future freezing rain events under future climate scenarios for south-central Canada. Synoptic weather typing consists of principal components analysis, an average linkage clustering procedure (i.e., a hierarchical agglomerative cluster method), and discriminant function analysis (a nonhierarchical method). Meteorological data used in the analysis included hourly surface observations from 15 selected weather stations and six atmospheric levels of six-hourly National Centers for Environmental Prediction (NCEP) upper-air reanalysis weather variables for the winter months (November-April) of 1958/59-2000/01. A statistical downscaling method was used to downscale four general circulation model (GCM) scenarios to the selected weather stations. Using downscaled scenarios, discriminant function analysis was used to project the occurrence of future weather types. The within-type frequency of future freezing rain events is assumed to be directly proportional to the change in frequency of future freezing rain-related weather types
\end{abstract}

The results showed that with warming temperatures in a future climate, percentage increases in the occurrence of freezing rain events in the north of the study area are likely to be greater than those in the south. By the 2050s, freezing rain events for the three colder months (December-February) could increase by about $85 \%$ (95\% confidence interval - CI: $\pm 13 \%), 60 \%$ (95\% CI: $\pm 9 \%$ ), and $40 \%(95 \% \mathrm{CI}: \pm 6 \%$ ) in northern Ontario, eastern Ontario (including Montreal, Quebec), and southern Ontario, respectively. The increase by the 2080s could be even greater: about $135 \%$ (95\% CI: $\pm 20 \%$ ),

Correspondence to: C. S. Cheng

(shouquan.cheng@ec.gc.ca)
95\% (95\% CI: $\pm 13 \%$ ), and $45 \%$ (95\% CI: $\pm 9 \%$ ). For the three warmer months (November, March, April), the percentage increases in future freezing rain events are projected to be much smaller with some areas showing either a decrease or little change in frequency of freezing rain. On average, northern Ontario could experience about $10 \%$ (95\% CI: $\pm 2 \%$ ) and $20 \%$ (95\% CI: $\pm 4 \%$ ) more freezing rain events by the 2050s and 2080s, respectively. However, future freezing rain events in southern Ontario could decrease about $10 \%$ (95\% CI: $\pm 3 \%$ ) and $15 \%$ (95\% CI: $\pm 5 \%$ ) by the 2050 s and 2080s, respectively. In eastern Ontario (including Montreal, Quebec), the frequency of future freezing rain events is projected to remain the same as it is currently.

\section{Introduction}

Freezing rain is a major hazard that impacts many industries, including transportation, energy, and commerce. It can bring about slippery driving and walking conditions, and cause damage to overhead wires, communication towers, and trees due to ice accumulation. Although major freezing rain events or ice storms are relatively rare (Cheng et al., 2004), the average damage sustained per event (nearly CDN $\$ 1.4$ billion) is by far the most costly among all Canadian hydrometeorological disasters (Dore, 2003). Regan (1998) reported that, across Quebec and Ontario, the Ice Storm of January 5-9, 1998 was responsible for 25 fatalities, left some one million householders without power, caused nearly US $\$ 3$ billion in damages, and resulted in another US $\$ 3$ billion in short-term lost economic output and insurance claims.

To diminish the devastating effects associated with these events, many previous studies used quantitative or qualitative methods to try to determine the relationships that exist between weather conditions and freezing rain events over the short term. Some of these studies are listed in Table 1. For various regions in North America and Europe, much of

Published by Copernicus GmbH on behalf of the European Geosciences Union. 
Table 1. Examples of previous studies on prediction and climatology of freezing precipitation.

\begin{tabular}{|c|c|c|c|}
\hline Methodology & Study & Type of Freezing Precipitation* & Study Area \\
\hline Case study & $\begin{array}{l}\text { Forbes et al. (1987) } \\
\text { Rauber et al. (1994) } \\
\text { Environment Canada (1998) } \\
\text { Jones and Mulherin (1998) } \\
\text { Regan (1998) } \\
\text { Milton and Bourque (1999) } \\
\text { Higuchi et al. (2000) }\end{array}$ & $\begin{array}{l}\text { Ice storm, Jan. 13-14 } 1980 \\
\text { Ice storm, Feb. 14-15 } 1990 \\
\text { Ice storm, Jan. 5-9 } 1998 \\
\text { Ice storm, Jan. 5-9 } 1998 \\
\text { Ice storm, Jan. 5-9 } 1998 \\
\text { Ice storm, Jan. 5-9 } 1998 \\
\text { Ice storm, Jan. 5-9 } 1998\end{array}$ & $\begin{array}{l}\text { Appalachians, USA } \\
\text { Illinois, USA } \\
\text { Canada } \\
\text { Northern New England, USA } \\
\text { Southcentral Canada } \\
\text { Quebec, Canada } \\
\text { Southcentral Canada and } \\
\text { Northeastern United States }\end{array}$ \\
\hline Regression for prediction & $\begin{array}{l}\text { Bocchieri (1980) } \\
\text { Huffman and Norman (1988) } \\
\text { Konrad (1998) }\end{array}$ & $\begin{array}{l}\text { Precipitation type (liquid, freez- } \\
\text { ing, frozen) } \\
\text { FZRA }\end{array}$ & $\begin{array}{l}\text { Contiguous United States } \\
\text { Contiguous United States } \\
\text { Appalachians, USA }\end{array}$ \\
\hline $\begin{array}{l}\text { Critical values of meteorologi- } \\
\text { cal variables for prediction }\end{array}$ & $\begin{array}{l}\text { Wagner (1957) } \\
\text { Keeter and Cline (1991) } \\
\text { Bourgouin (2000) } \\
\text { Cortinas et al. (2002) } \\
\text { Czys et al. (1996) }\end{array}$ & $\begin{array}{l}\text { Precipitation type (rain, snow, } \\
\text { FZRA, PL) except Czys et } \\
\text { al. (1996) (distinguish between } \\
\text { FZRA and PL) }\end{array}$ & $\begin{array}{l}\text { Contiguous United States } \\
\text { North Carolina, USA } \\
\text { Contiguous United States } \\
\text { Contiguous United States } \\
\text { Contiguous United States }\end{array}$ \\
\hline Synoptic weather pattern & Rauber et al. (2001) & FZRA and FZDZ & USA east of the Rockies \\
\hline $\begin{array}{l}\text { Synoptic weather types and lo- } \\
\text { gistic regression for prediction }\end{array}$ & Cheng et al. (2004) & FZRA & Ottawa, Canada \\
\hline
\end{tabular}

* FZRA: freezing rain; FZDZ: freezing drizzle; PL: ice pellets

the emphasis over the past few decades with respect to predicting freezing rain or precipitation types has been in three main areas: First, attempts have been made to develop statistical models (e.g., critical thresholds, regression, Model Output Statistics - MOS, synoptic weather types or patterns) that will improve the accuracy of short-term freezing rain forecasts. The other two areas of focus have been on analyzing the climatology of freezing precipitation and carrying out case studies of individual freezing rain events. To date, very few studies have investigated the possible impacts of climate change on freezing rain events. The purpose of the current study is to use downscaled Canadian and US general circulation model (GCM) scenarios to estimate the occurrence frequency of future freezing rain events in southcentral Canada for two time periods (2040-2059 and 20702089). This study offers decision makers the necessary scientific information to improve the adaptive capacity of infrastructure at risk of being impacted by freezing rain in south- 
central Canada. This same information may also help reduce or eliminate the long-term risks to people, communities, and properties of the effects of climate change. The current study builds upon the method of Cheng et al. (2004), which was designed to predict the occurrence of freezing rain events using automated synoptic weather typing.

The projections from GCMs are currently used as scenarios of a future warmer climate. However, due to their coarse spatial resolution, typically $300 \mathrm{~km} \times 300 \mathrm{~km}, \mathrm{GCMs}$ are restricted in their usefulness for studying local impacts and determining sub-grid weather phenomena (Wigley et al., 1990; Grotch and MacCracken, 1991; Huth, 1999; Wilby et al., 2002; Penlap et al., 2004). As a result, GCM outputs must be converted or downscaled to specific weather stations of interest, from which historical observed weather data can be used to study local impacts. One of the leading techniques for such study is statistical (empirical) downscaling (Hewitson and Crane, 1996; Wilby and Wigley, 1997). Compared with other downscaling methods (e.g., dynamical downscaling), the main strengths of the statistical method are that it is relatively easy to apply and it has the ability to obtain stationscale climate information from GCM-scale output (Wilby et al., 2002). Since station-scale weather information was required in this case to study the impacts of climate change on freezing rain, statistical, or regression, downscaling was used to downscale GCM outputs to the 15 selected weather stations.

Many previous studies have used regression-based downscaling methods, which rely on empirical relationships between local-scale predictands and regional-scale predictors, to downscale daily and monthly GCM scenarios. These studies are differentiated from one another according to three major aspects: 1) statistical fitting procedures, 2) the selection of predictor variables, and 3) predictands (Wilby et al., 2002). To date, downscaling by statistical means has been increasingly developed using various statistical fitting procedures, including linear regression (e.g., Kim et al., 1984; Wigley et al., 1990; Carbone and Bramante, 1995; Schubert and Henderson-Sellers, 1997; Huth, 1999; Kettle and Thompson, 2004), canonical correlation analysis (e.g., von Storch et al., 1993; Penlap et al., 2004), and artificial neural networks (e.g., Hewitson and Crane, 1992, 1996). However, few previous studies have been conducted to downscale hourly weather variables; such downscaling is essential to assess local impacts of climate change on short-duration weather events (e.g., freezing rain). This current study will derive hourly future weather scenarios of temperature, dew point, west-east and south-north wind velocities at the surface and six upper atmospheric levels as well as mean sea-level air pressure and total cloud cover. These hourly weather variables are required to determine future synoptic weather types and the linkage to freezing rain in this study.

The organization of this paper is as follows. In Sect. 2, data sources and their treatments are described. Section 3 describes the analysis techniques as applied to 1) statistical downscaling, 2) synoptic weather typing, and 3) estimation of changes in occurrence frequency of future freezing rain events. Section 4 describes model validation including verification of freezing rain-related weather types and downscaling transfer functions. Sections 5 and 6 include the results and discussion, respectively. The conclusions from the study are summarized in Sect. 7. We hope this study provides some insight into the future vulnerability of various industries (e.g., transportation, energy, commerce) to freezing rain events and provides them with scientific information in adapting to and managing the associated risks.

\section{Data sources and treatment}

Hourly surface meteorological data for 14 stations in Ontario and one station in Montreal, Quebec were retrieved from Environment Canada's Digital Archive of Canadian Climatological Data for six winter months (November-April) of 1958/59-2000/01 (the selected stations are shown in Fig. 1). The meteorological data used in this study included hourly weather station observations of air temperature $\left({ }^{\circ} \mathrm{C}\right)$, dew point temperature $\left({ }^{\circ} \mathrm{C}\right)$, sea-level air pressure $(\mathrm{hPa})$, total cloud cover (tenths of sky cover), wind speed $\left(\mathrm{m} \mathrm{s}^{-1}\right)$, wind direction (degrees), and occurrence of freezing rain (1 for yes, 0 for no). A sine-cosine transformation was used to convert wind speed and direction into west-east and southnorth scalar velocities. With the exception of freezing rain occurrence, when the data were missing for three consecutive hours or less, missing data were interpolated using a temporal linear method; days with data missing for four or more consecutive hours were excluded from the analysis. After interpolation, the station data across the study area were complete for $>99.5 \%$ of the days in the November-April period of 1958/59-2000/01.

The six-hourly upper-air reanalysis weather data were retrieved from the U.S. National Centers for Environmental Prediction (NCEP) website. The reanalysis data at 06:00, 12:00, 18:00, and 00:00 UTC for the November-April period of 1958/59-2000/01 were used in the study. The data included a variety of meteorological variables, including air temperature $\left({ }^{\circ} \mathrm{C}\right)$, relative humidity $(\%)$, and west-east and south-north wind velocities $\left(\mathrm{m} \mathrm{s}^{-1}\right)$ on a $2.5^{\circ} \times 2.5^{\circ}$ latitudelongitude grid at six standard air pressure levels (1000, 925 , $850,700,600$ and $500 \mathrm{hPa}$ ). To combine the gridded reanalysis data with the surface weather data, the reanalysis data were interpolated to the selected weather stations using the inverse-distance method (Shen et al., 2001).

For this study, the NCEP reanalysis relative humidity data were converted into dew point temperature based on Tetens' equation (Berry et al., 1945). Dew point temperature was preferred over relative humidity since it is highly conservative on a diurnal level and moderately conservative among various micro-environments (Kalkstein and Corrigan, 1986). In weather impacts analysis, it is preferred as a measure over 


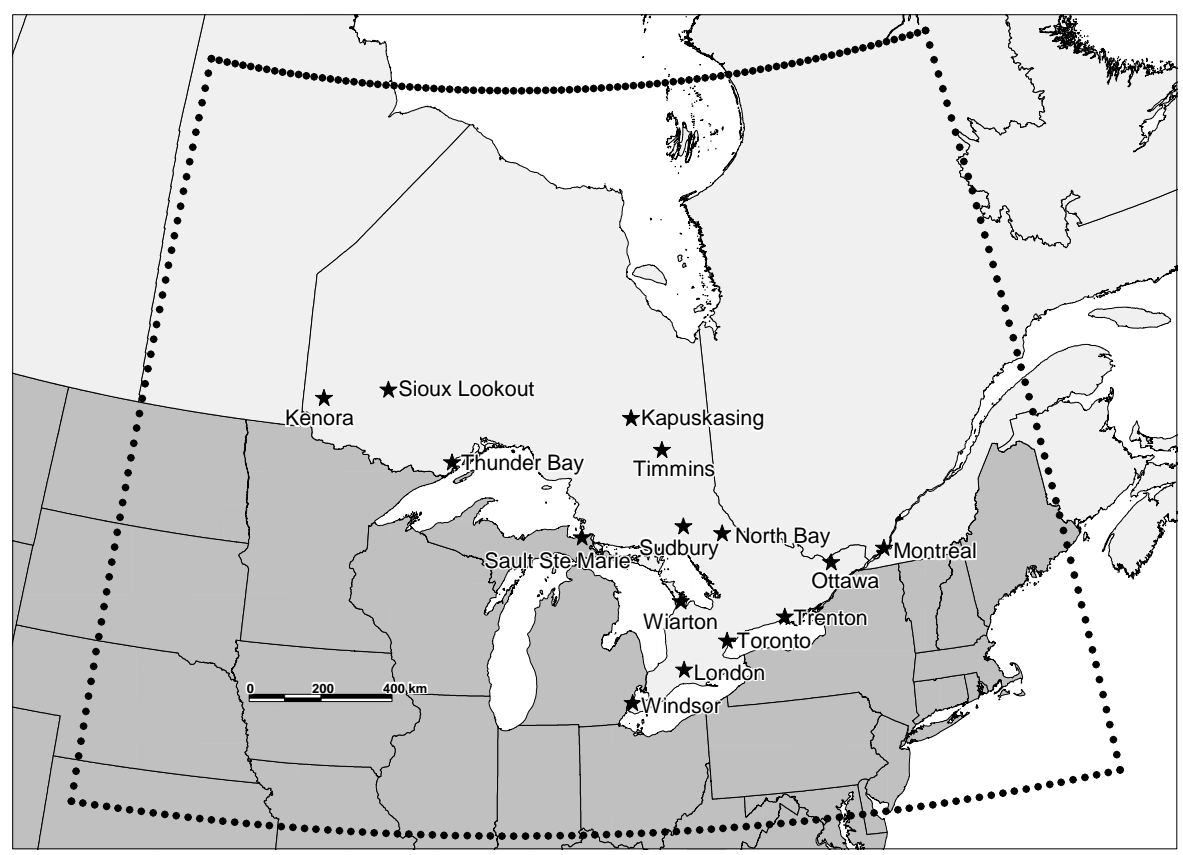

Fig. 1. Location map of study points and the regional downscaling model domain.

relative humidity, which, in the early morning from summer to winter, remains at a relatively high constant. Although there was no missing data within the reanalysis dataset, there were a few cases where relative humidity values were identically zero, even in the lower levels. These values were not physically realistic, and they were excluded from the analysis. The number of days on which this occurred was small; for example, at Ottawa, out of the entire data record only five days of reanalysis data were excluded.

Daily climate change scenarios from three Canadian GCMs and one U.S. GCM for two time windows (November-April, 2040/41-2058/59 and 2070/71-2088/89) were used in the analysis. Canadian GCMs include the first generation coupled GCM - CGCM1 IPCC IS92a (IPCC Scenario 92a) and the second generation coupled GCM CGCM2 IPCC SRES A2 and B2. The U.S. GCM is the Geophysical Fluid Dynamics Laboratory - GFDL R30 Coupled Climate Model IPCC SRES A2 (Delworth et al., 2002). From Environment Canada's website (Environment Canada, 2005), it is seen that the IS92a scenario is similar to the IPCC "business-as-usual" scenario. Compared to the IS92a scenario, the A2 scenario projects slightly lower GHG emissions and aerosol loadings in future; as a result, the projected warming response differs slightly between the two scenarios. The B2 scenario produces much lower emissions and less future warming, especially in the second half of the 21 st century.

The two time windows represent the time frame in which atmospheric equivalent $\mathrm{CO}_{2}$ (at IS92a scenario greenhouse gas forcing) is expected to double and triple, respectively, from 1975-1995 levels (Environment Canada, 2005). In addition, the historical runs of the CGCM1 and CGCM2 from November-April 1961/62-1999/2000 were used to correct the model bias; historical runs were not available, however, for the GFDL model. Consequently, estimated changes in future freezing rain due to climate change based on the GFDL climate change scenarios might have a higher degree of uncertainty than those based on CGCM outputs.

\section{Analysis techniques}

\subsection{Statistical downscaling methods}

The statistical downscaling methods consist of five steps: first, the reanalysis data $\left(2.5^{\circ} \times 2.5^{\circ}\right)$ were re-gridded to the CGCM $\left(3.75^{\circ} \times 3.75^{\circ}\right)$ and GFDL $\left(3.75^{\circ} \times 2.25^{\circ}\right)$ model grids. A variety of domains was tested by comparing the data distribution between downscaled daily mean temperatures of the CGCM1 historical run (1961-2000) with observations over the same time period. The test results indicated that the domain shown in Fig. 1 is most suitable for downscaling in the study area. Second, the correlation-matrixbased principal components analysis (PCA) was applied to the domain for all days within the season (November-April) from 1958/59 to 2000/01 for each of the reanalysis weather elements. PCA can identify a reduced set of uncorrelated variables that can account for most spatial relationships in the original dataset (Schubert and Henderson-Sellers, 1997). The spatial relationships can remove some bias from the large scale GCM output that cannot reproduce meaning- 
Table 2. Predictors for development of daily downscaling transfer functions.

\begin{tabular}{ll}
\hline $\begin{array}{l}\text { Predictand - Observations at } \\
\text { weather stations (daily mean) }\end{array}$ & $\begin{array}{l}\text { Predictors - PCA in the domain field } \\
\text { from the NCEP reanalysis data (daily mean) }\end{array}$ \\
\hline $\begin{array}{l}\text { Maximum temperature } \\
\text { Minimum temperature }\end{array}$ & $\begin{array}{l}\text { Maximum temperature, Temperature at } 850 \text { and } 500 \mathrm{hPa} \\
\text { Minimum temperature, Temperature at } 850 \text { and } 500 \mathrm{hPa}\end{array}$ \\
$\begin{array}{l}\text { Daily mean air temperature } \\
\text { U-wind at surface }\end{array}$ & $\begin{array}{l}\text { Daily mean air temperature, Temperatures at } 850 \mathrm{and} 500 \mathrm{hPa} \\
\text { Sea level pressure }\end{array}$ \\
V-wind at surface & U-wind, Pressure difference between east and west grid points \\
Temperature at 850 or $500 \mathrm{hPa}$ & V-wind, Pressure difference between north and south grid points \\
U-wind (V-wind) at 850 or $500 \mathrm{hPa}$ & Temperature at 850 or $500 \mathrm{hPa}$ \\
\hline
\end{tabular}

ful local-scale climate information (Bárdossy, 1994; Bass and Brook, 1997). Third, the regression-based downscaling procedure was employed to analyze the relationships between the observed elements at a single site (the selected stations) and the PCA component variables derived from the re-gridded NCEP reanalysis data field. Fourth, component scores for each day of the future climate scenarios were determined by multiplying the post-eigenvector matrix (derived from the second step above) by the standardized future climate scenario field. To reduce the GCM bias, the future climate scenario field was standardized by the means and standard deviations of the GCM historical runs (1961-2000). As daily GFDL historical runs are not available, the GFDL scenario means from monthly historical runs and standard deviations of 2010-29 were used to standardize future GFDL outputs. The new component scores derived for future climate scenarios are comparable to the PCA scores used in regression analysis since both use the same eigenvector matrix. These scores were applied to regression algorithms to generate downscaled daily GCM scenarios for each of the elements at each of the selected stations. Finally, following the daily GCM downscaling, the future hourly downscaling scenarios were derived using the relationships between the hourly observation and its daily mean as well as other weather predictors, where appropriate.

The predictors used to develop daily and hourly downscaling transfer functions are listed in Tables 2 and 3, respectively. To avoid multicollinearity between explanatory variables, principal component scores were once again used as predictors, instead of the linearly inter-correlated weather variables. Different regression methods were used to construct transfer functions for different weather variables. Multiple stepwise regression analysis was used for all weather variables except total cloud cover. Cumulative logit regression was used as a more suitable analysis of cloud cover since cloud cover is an ordered categorical data format (Allison, 1999). These historical relationships derived from the past 40 years were assumed to remain constant in the future. This assumption is reasonable since future physical coherence within meteorological processes and weather patterns is expected to remain similar to that of the recent past. Furthermore, based on the relationships, the downscaling method allows future weather variable values to be estimated as temperatures increase under various climate change scenarios.

The GCM output of specific humidity was not used in the study for downscaling since approximately $40-60 \%$ of daily mean dew point temperatures derived from the GCM specific humidity were greater than the GCM outputs of temperatures for the selected stations. Hourly future dew point temperatures were derived from the historical associations between hourly dew point temperature and hourly temperature as well as other weather variables (listed in Table 3) every $24 \mathrm{~h}$. The GCM output of total cloud cover was not used in the study because there were no spatial relationships between total cloud cover observations at each of the selected stations and the corresponding principal component scores derived from the NCEP reanalysis data (model $\mathrm{R}^{2}<0.1$ ). The PCA scores calculated from a variety of weather variables, such as surface and upper-air corresponding hourly temperature, dew point temperature depression, south-north/west-east winds, and sea-level air pressure, were used to develop downscaling transfer functions for total cloud cover (Table 3).

\subsection{Automated synoptic weather typing}

An automated synoptic typing procedure, based primarily on air mass similarity and differentiation within and between weather types, was used to assign every day of the dataset to a distinctive weather type during the season (NovemberApril) from 1958/59 to 2000/01. The entire suite of 240 weather variables, including 144 surface and 96 upper-air variables, was used in the classification. The 144 surface variables are produced from hourly weather elements of air temperature, dew point temperature, sea-level air pressure, total cloud cover, and south-north and west-east scalar wind velocities over a $24 \mathrm{~h}$ period. The 96 upper-air reanalysis variables are comprised of six-hourly weather elements of air temperature, dew point temperature, and south-north and west-east scalar wind velocities, at six atmospheric levels. 
Table 3. Predictors for development of hourly downscaling transfer functions (surface: hourly; upper-air: 06:00, 12:00, 18:00, 00:00 UTC).

\begin{tabular}{|c|c|}
\hline $\begin{array}{l}\text { Predictand (surface: hourly; } \\
\text { upper-air: six-hourly) }\end{array}$ & Predictors (daily mean or hourly values) \\
\hline Surface temperature & $\begin{array}{l}\text { CGCM: Surface maximum and minimum temperatures } \\
\text { GFDL: Surface daily mean temperature }\end{array}$ \\
\hline Sea level pressure & Daily mean sea level pressure \\
\hline Temperature at $925 \mathrm{hPa}$ & Hourly temperatures at surface and $850 \mathrm{hPa}$ \\
\hline Temperature at $850 \mathrm{hPa}$ & Daily mean temperature at $850 \mathrm{hPa}$ \\
\hline Temperature at 700 or $600 \mathrm{hPa}$ & Daily mean temperature at $850 \mathrm{hPa}$ and $500 \mathrm{hPa}$ \\
\hline Temperature at $500 \mathrm{hPa}$ & Daily mean temperature at $500 \mathrm{hPa}$ \\
\hline $\mathrm{U}$-wind (V-wind) at $925 \mathrm{hPa}$ & Hourly U-wind (V-wind) at surface and $850 \mathrm{hPa}$ \\
\hline $\mathrm{U}$-wind ( $\mathrm{V}$-wind) at $850 \mathrm{hPa}$ & Daily mean U-wind (V-wind) at $850 \mathrm{hPa}$ \\
\hline $\mathrm{U}$-wind (V-wind) at 700 or $600 \mathrm{hPa}$ & Daily mean U-wind (V-wind) at 850 and $500 \mathrm{hPa}$ \\
\hline \multirow[t]{2}{*}{$\mathrm{U}$-wind (V-wind) at $500 \mathrm{hPa}$} & Daily mean U-wind (V-wind) at $500 \mathrm{hPa}$ \\
\hline & PCA predictors were used below \\
\hline U-wind at surface & $\begin{array}{l}\text { Surface daily mean U-wind, Surface hourly temperature, Hourly sea-level } \\
\text { pressure difference from the previous three hours }\end{array}$ \\
\hline V-wind at surface & $\begin{array}{l}\text { Surface daily mean V-wind, Surface hourly temperature, Hourly sea-level } \\
\text { pressure difference from the previous three hours }\end{array}$ \\
\hline Dew point at surface & $\begin{array}{l}\text { Surface: Hourly sea level pressure, Hourly temperature, Hourly U- and V-wind } \\
850 \text { and } 500 \mathrm{hPa} \text { : Daily mean temperature, Hourly U- and V-wind }\end{array}$ \\
\hline Total cloud cover & $\begin{array}{l}\text { Surface: Hourly temperature, Hourly sea level pressure, Hourly dew point } \\
\text { depression } \\
\text { Temperature difference (surface- } 850 \mathrm{hPa} \text { ) at } 01: 00 \text { and 13:00 } \\
\text { Daily mean V-wind at } 850 \mathrm{hPa}\end{array}$ \\
\hline $\begin{array}{l}\text { Dew point at } 925,850,700,600, \text { or } \\
500 \mathrm{hPa}\end{array}$ & $\begin{array}{l}\text { Surface: Daily mean sea level pressure, Hourly temperature and total cloud } \\
\text { cover } \\
850 \text { and } 500 \mathrm{hPa} \text { : Daily mean temperature and V-wind } \\
\text { Air pressure level at the question: Hourly temperature and V-wind }\end{array}$ \\
\hline
\end{tabular}

The weather typing procedure used in this study consists of two steps: 1) temporal synoptic weather types were categorized using PCA and an average linkage clustering procedure (a hierarchical agglomerative cluster method), and 2) all days in the dataset were regrouped by discriminant function analysis (a nonhierarchical method) using the centroids of the hierarchical weather types as seeds. Previous studies have pointed out that the combination of hierarchical and nonhierarchical classification methods produces better classification results with smaller within-cluster variances and larger between-cluster variances (Huth et al., 1993; DeGaetano, 1996).

The correlation matrix-based PCA was performed to reduce the 240 intercorrelated weather variables into a small number of linearly independent component variables, explaining much of the variance within the original dataset. Days with similar meteorological situations will tend to exhibit approximately similar component scores. The average linkage clustering procedure generated statistical diagnostics to produce an appropriate number of clusters (for details, refer to Boyce, 1996; Cheng and Lam, 2000; Cheng et al., 2004), and then classified those days with similar component scores into one of the meteorologically homogeneous groups. Following the initial classification, discriminant function analysis was used to reclassify all days within the dataset using the centroids of the hierarchical weather types as seeds.

Discriminant function analysis was also used to determine future daily weather types using downscaled hourly climate change scenarios. To compare component scores from both historical and future datasets, component scores for each of the future days were calculated by multiplying the post-eigenvector matrix (derived from the data for the period November-April, 1958/59-2000/01) by the standardized future weather data matrix. To remove the GCM model bias, future downscaled hourly scenarios were standardized using the mean and standard deviation of the GCM historical runs. Using the centroids of the predetermined weather types derived from the observations as seeds, discriminant function analysis can assign each of the future days into one of the predetermined historical weather types based on the component scores. This method is proposed to be an appropriate approach in light of a changing climate since discriminant function analysis could assign future days with a simulated 


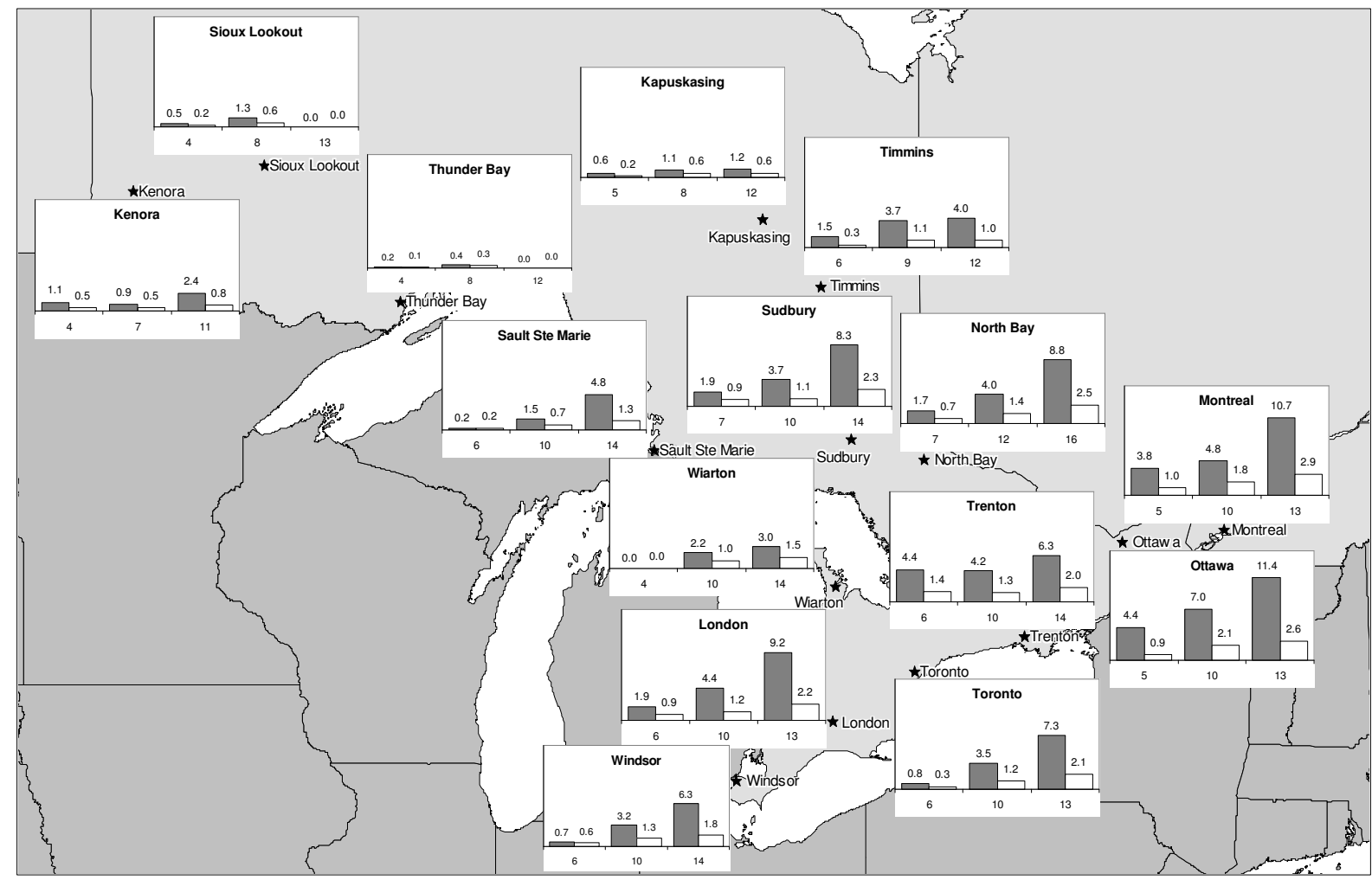

Fig. 2. Monthly mean total hours (grey bar) and days (white bar) of freezing rain events within each of the triciles of monthly total number of days with the freezing rain-related weather types in January, 1959-2001 (the horizontal axis is within-tricile monthly mean number of days with the freezing rain-related weather types).

higher temperature beyond the range of the historical observations into the warmest weather group. These cases could be rare (typically $<1 \%$ of the future days) because many of the future days could be warmer than the current days instead of warmer than the historical record (Dettinger et al., 2004; Hayhoe et al., 2004).

\subsection{Estimation of occurrence frequency of future freezing} rain events

The occurrence frequency of future freezing rain events was estimated based on within-weather-type frequency of historical freezing rain events and changes in the frequency of future synoptic types. The within-type frequency of future freezing rain events is assumed to be directly proportional to the change in frequency of future freezing rain-related weather types. The annual mean total number of future freezing rain days $\left(N^{f}\right)$ was estimated using this expression,

$N^{f}=\sum_{i=1}^{n}\left(\frac{\operatorname{Freq}_{i}^{f}}{\operatorname{Freq}_{i}^{h}} \times N_{i}^{h}\right)$,

where $n$ is the number of all weather types, $\mathrm{Freq}_{i}^{h}$ and Freq $_{i}^{f}$ are the percentage frequencies of weather type $i$ for historical and future periods, and $N_{i}^{h}$ is the annual mean total number of historical freezing rain days within weather type $i$.

This assumption is based on an expectation that the yearto-year fluctuations of freezing rain occurrences are closely associated with the occurrence frequencies of the freezing rain-related weather types. To investigate this relationship, the tricile method was used. Monthly total occurrence frequencies of the freezing rain-related weather types were sorted. The months were then divided into three groups based on a one-third interval of the difference between the highest and lowest monthly frequencies. Within-tricilegroup mean frequencies of freezing rain occurrences and mean frequencies of freezing rain-related weather types are shown in Fig. 2. In general, monthly frequency of freezing rain events increases with the frequency of freezing rainrelated weather types across the study area. For example, in Ottawa, on average in January, as the monthly total occurrence frequency of freezing rain-related weather types increases from 5 to 10 to 13 , the monthly total hours of freezing rain occurrence increase from 4.4 to 7.0 to 11.4 ; the monthly total number of days with freezing rain events increases from 0.9 to 2.1 to 2.6. Similar results are also found for other months (i.e., December and February) but are not shown here due to limitations of space. Based on both monthly total 


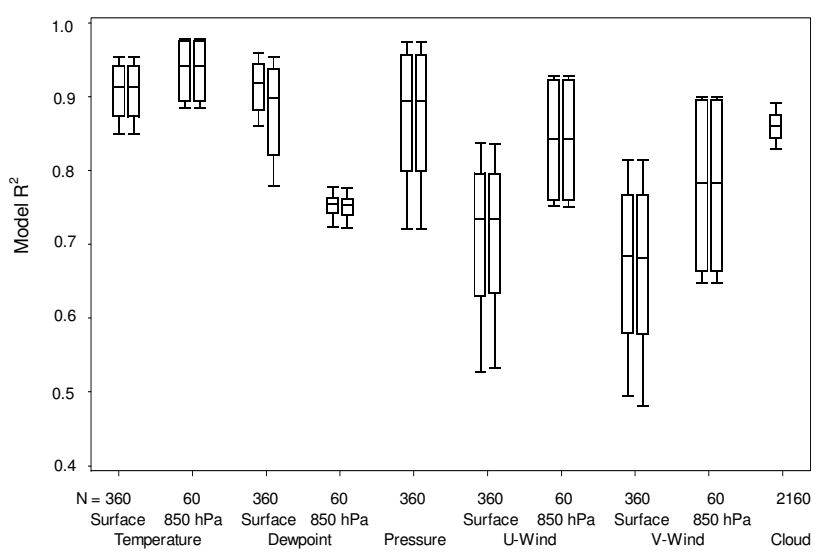

Fig. 3. Quartile box-plot of coefficient of determination $\left(\mathrm{R}^{2}\right)$ for all hourly climate change scenario transfer functions at 15 selected sites. The boxes represent model development (left box) and verification using a cross-validation scheme (right box). Concordance is used to measure the model performance for total cloud cover resulting from cumulative logit regression. $\mathrm{N}$ represents the number of functions.

hours and days of freezing rain events, average number of hours per day when freezing rain is observed, is calculated as $4.9,3.3$, and 4.4 hours/day. Unlike freezing rain events, the average number of hours per day is not typically affected by the frequency of freezing rain-related weather types. This suggests that a lower monthly occurrence of freezing rainrelated weather types will result in fewer monthly total hours or days of freezing rain events. However, the average number of hours per day within freezing rain events will not be affected

\section{Model validation}

\subsection{Synoptic weather typing}

The PCA is applied to the 240 weather variables for all days within the season from $1958 / 59$ to $2000 / 01$ for all 15 stations, producing an 18-component solution that explains $91 \%$ of the total variance within the dataset. The remainder of the components with eigenvalues less than one was discarded. The thermal and moisture variables (i.e., air temperature and dewpoint temperature) highly load on component 1 , which explains over $36 \%$ of the total variance. Half of the total variance for sea-level pressure and total cloud cover contributes to this component; south-north wind velocity aloft also contributes to this component. The loadings for component 2 , which explain an additional $13 \%$ of the total variance, are dominated by west-east wind velocity and sea-level pressure. Component 3 , which explains over $11 \%$ of the variance, is largely loaded by south-north surface wind velocity and winds aloft. Component 4 , which explains close to an additional $9 \%$ of the variance, is largely determined by sea-level pressure and total cloud cover. Nearly half of the total variance for both sea-level pressure and total cloud cover contributes to this component. The remaining components 5-18 explain nearly $22 \%$ of the total variance and largely comprise terms to describe the diurnal changes of the variables.

A hierarchical method-the average linkage clustering procedure-performed on the daily 18-component scores resulted in 18 major synoptic weather types $(>1 \%$ of the total days) for the study area for all days within the season November-April, 1958/59-2000/01, based primarily on differences in their meteorological characteristics. A nonhierarchical method-discriminant function analysis-was used to reclassify all days within the dataset using the centroids of the hierarchical weather types as seeds. The number of weather types with sizes above $1 \%$ of the total days, resulting from discriminant function analysis, was increased from, for example, 18 to 23 for Ottawa, which captured about $94 \%$ of the total days. Improvement in the cluster structure resulting from nonhierarchical reclassification was evaluated by comparing within-/between-cluster variances. The reclassification results were better with smaller within-cluster variances and larger between-cluster variances. The variance $F$ ratio (the between-group variance over the within-group variance) resulting from the reclassification increased by 10 $30 \%$ for all weather variables observed at 12:00 UTC. These results were consistent with previous studies (e.g., DeGaetano, 1996).

Following synoptic weather typing, it is possible to identify the weather types most highly associated with freezing rain events. To achieve this, the $\chi^{2}$-test was employed to ascertain whether the observed frequency of freezing rain cases (actual frequency) within each of these weather types was significantly higher than its expected frequency - the size of the weather type. For more information on the identification of the freezing rain-related weather types, please refer to Cheng et al. (2004). Based upon this procedure, four weather types were identified as the primary freezing rain weather types for all 15 selected stations; up to two additional weather types were identified at selected stations. These freezing rain-related weather types accounted for $75-100 \%$ of the freezing rain events that occurred on $\geq 1$ to $\geq 6 \mathrm{~h}$ during a day over the entire study period.

\subsection{Statistical downscaling}

The regression models showed very strong correlations between predictands and predictors. The coefficients of determination $\left(\mathrm{R}^{2} \mathrm{~s}\right)$ of downscaling transfer functions for variables at the surface and at $850 \mathrm{hPa}$ are shown in Fig. 3 as examples. There are 360 multiple regression models in total for each of the surface weather elements (except for cloud cover), created by taking measurements 24 times per day in 15 cities. There are 60 transfer functions for the weather elements at each of the upper-air levels, since measurements are taken four times per day. Hourly total cloud cover downscal- 
ing transfer functions were developed on a monthly basis, as the amount of cloud cover, especially overcast conditions, significantly varies from month to month. As a result, observations taken 24 times per day, over six months, in 15 cities produce 2160 transfer functions.

From Fig. 3 it is clear that almost all of the temperature and air pressure transfer functions possessed model $\mathrm{R}^{2}>0.85$. The transfer functions for surface south-north winds ( $v$-wind) represented the weakest model of the weather elements; however, model $\mathrm{R}^{2} \mathrm{~s}$ were still very high, ranging from 0.5 to 0.8 with half of them greater than 0.69 . It is noteworthy that transfer function model $\mathrm{R}^{2} \mathrm{~s}$ for temperature and winds aloft are usually greater than those at the surface. However, the model $\mathrm{R}^{2}$ of dew point transfer functions generally decreases from 925 to 850 to $500 \mathrm{hPa}$ (averaging $\mathrm{R}^{2}=0.93,0.75$, and 0.58 ). One of the possible reasons is that dew point transfer functions rely on relationships with temperature; the coefficient of determination $\left(\mathrm{R}^{2}\right)$ between dew point and temperature at the lower level is much greater than at the higher level (for example, at 18:00 UTC in Ottawa, $\mathrm{R}^{2}=0.8,0.5$, and 0.3 at 925,850 , and $500 \mathrm{hPa}$, respectively). Unlike multiple regression analysis, cumulative logit regression used concordance to measure the model performance. Of the 2,160 models, the concordances ranged from 0.79 to 0.92 with over $50 \%$ greater than 0.86 . It was concluded that the downscaling methods used in the study were suitable for deriving station-scale hourly GCM scenarios since downscaling transfer functions showed very strong correlations between observations and model predictions.

When regression analysis is used to develop downscaling transfer functions, the transfer functions need to be validated, using an independent dataset, to ensure the models are not over-fitted. To achieve this, a cross-validation scheme was employed to validate all transfer functions for each of the elements. The regression procedure was repeatedly run to develop a transfer function that would validate one-year of independent data for each year in the data set. The validated data were then compared with observations to calculate the coefficients of determination $\left(\mathrm{R}^{2} \mathrm{~s}\right)$, which are shown in Fig. 3. As can be seen from Fig. 3, model $R^{2} s$ from model development and cross-validation are similar. For total cloud cover, it is difficult and unnecessary to calculate concordance for the validation results. Hourly cloud cover validations for all stations were compared with observations to calculate the hourly absolute difference (HAD) between the two. The results show that about $61 \%$ of the total hours have HAD values $\leq 1$; while $20 \%$ have the values $\geq 5$. When hourly cloud cover validations are compared with model calibrations, the proportion with HAD values $\leq 1$ is about $96 \%$. Therefore, the downscaling transfer functions for all weather variables used in the study are reliable and over-fitting is not an issue.

The performance of hourly downscaling transfer functions varies for different times of day. For all weather variables except dew point temperature and cloud cover, hourly downscaling transfer functions during the day usually perform bet-
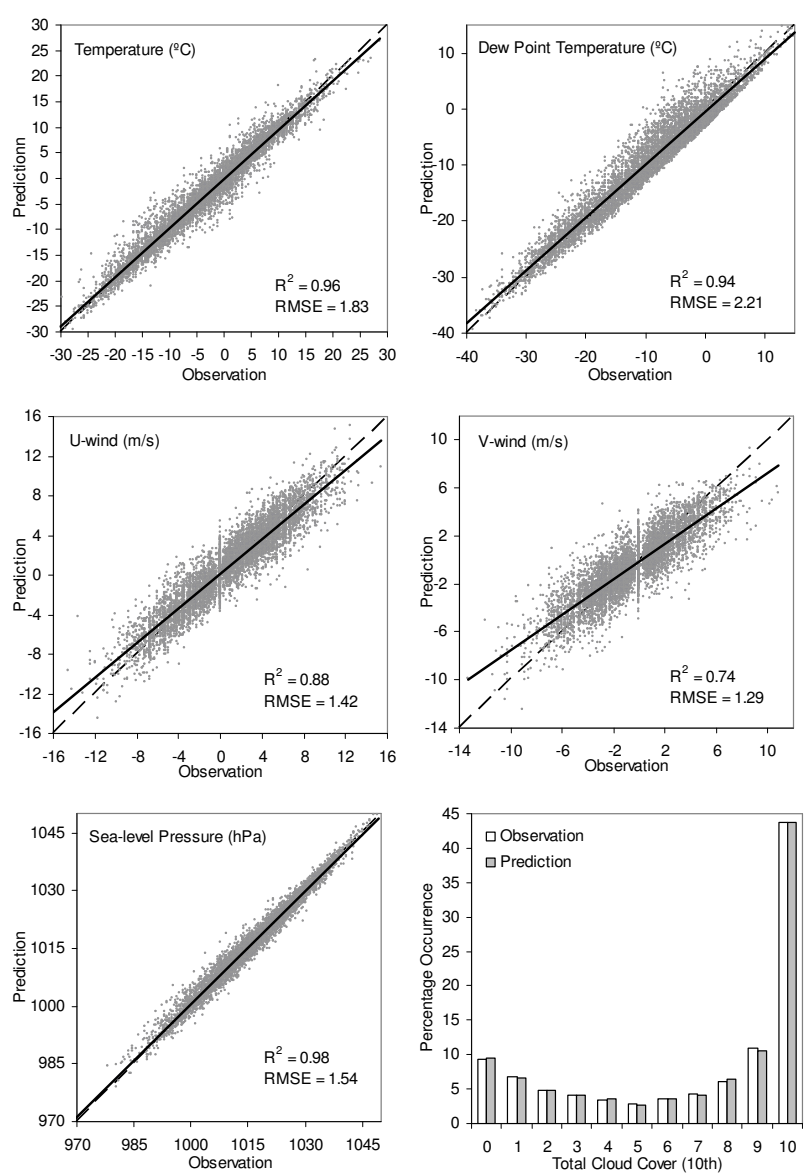

Fig. 4. Relationships between observations and model verification using a cross-validation scheme for surface weather elements in Ottawa for the period November-April, 1958/59-2000/01 (dew point temperature at 11:00 UTC; the rest of the elements at 16:00 UTC).

ter than those during the night. For dew point temperature, hourly downscaling transfer functions during the morning are usually stronger than those during the afternoon. Total cloud cover transfer functions do not seem to be affected by time of day. To further evaluate the performance of hourly downscaling transfer functions, besides model $R^{2} s$, model validations and observations were plotted, for example, for surface weather elements in Ottawa (Fig. 4). One of the best model validations at 16:00 UTC for all weather elements except dew point temperature was selected to graphically illustrate the model performance in Fig. 4. The validations at 1100 UTC for dew point temperature were used. The results suggest that the models developed in the study performed well in predicting historical weather data and can thus be used to downscale climate change scenarios.

In addition to validating the downscaling transfer functions using historical observations, the performance of the downscaling transfer functions was evaluated using CGCM historical runs (CGCM1 and CGCM2). The data distri- 


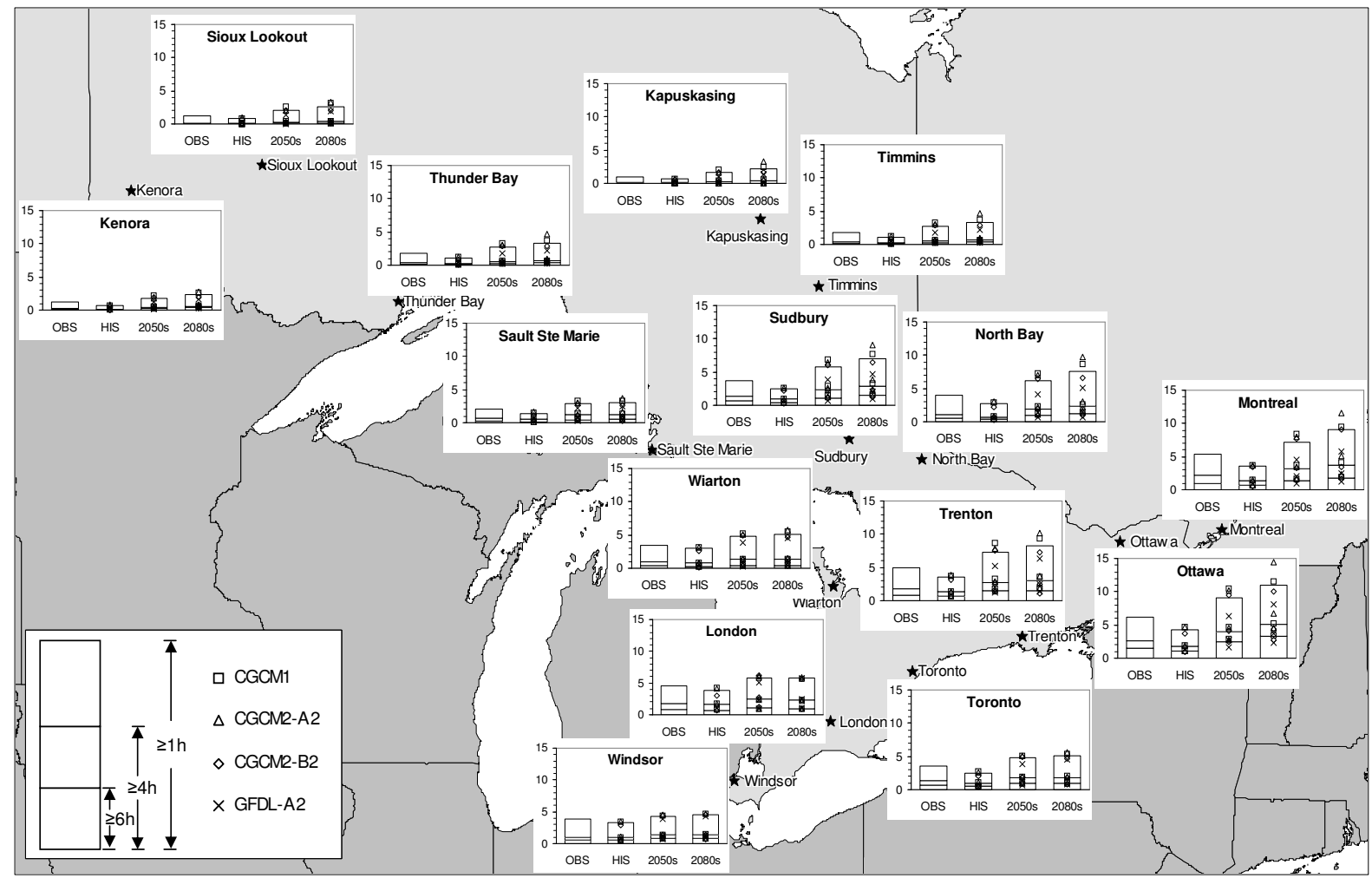

Fig. 5. Mean three-month total number of freezing rain events that occurred $\geq 1, \geq 4$, and $\geq 6 \mathrm{~h}$ during a day under the current climate during the period December-February, 1961-2000 (the left two bars) and future time periods (2040-2069, 2070-2089) (the right two bars). OBS represents observation and HIS is CGCM historical runs.

butions resulting from downscaled CGCM historical runs (1961-2000) were compared with observations/reanalysis data over the same time period. If the data distribution of downscaled GCM historical runs was significantly close to that of observations, we would then be confident in deriving future climate change information on a local scale (Bürger, 1996). The statistical Kolmogorov-Smirov (K-S) test was employed to ascertain whether the two data distributions were similar (Davis, 1986). In this study, the computed K$\mathrm{S}$ test statistic for each of the weather variables was much smaller than the corresponding critical value. Therefore, the null hypothesis that the data distribution of the downscaled GCM historical run is similar to that of observations cannot be rejected. Data distributions of downscaled GCM historical runs for all weather variables used in the study are significantly similar to those of observations (due to limitations of space, the results are not shown here). However, we suggest that even small differences need to be considered to further correct the GCM and downscaling model biases when analyzing local impacts of climate change.

\section{Results}

To estimate changes in the occurrence frequency of future freezing rain events, discriminant function analysis was used to assign each day of two future windows of time (November-April, 2040/41-2058/59 and 2070/71-2088/89) into one of the weather types pre-determined from the observations (November-April, 1958/59-2000/01). Although discriminant function analysis is suitable to identify or predict weather types using observations, its performance on future weather type verification needs to be evaluated. This was done in two ways.

First, the occurrence frequency of freezing rain-related weather types derived from downscaled CGCM historical runs was compared with that derived from observations over the same time period (November-April, 1958/59-2000/01). On average across the study area, the occurrence frequency of freezing rain-related weather types derived from CGCM historical runs was $4.8 \%$ (ranging from $2.6 \%$ to $8.5 \%$ ) slightly less than that derived from observations.

Second, the mean annual number of freezing rain events that occurred for $\geq 1, \geq 4$, and $\geq 6 \mathrm{~h}$ during a day, associated with the freezing rain-related weather types, was evaluated for both observations and the downscaled CGCM historical 


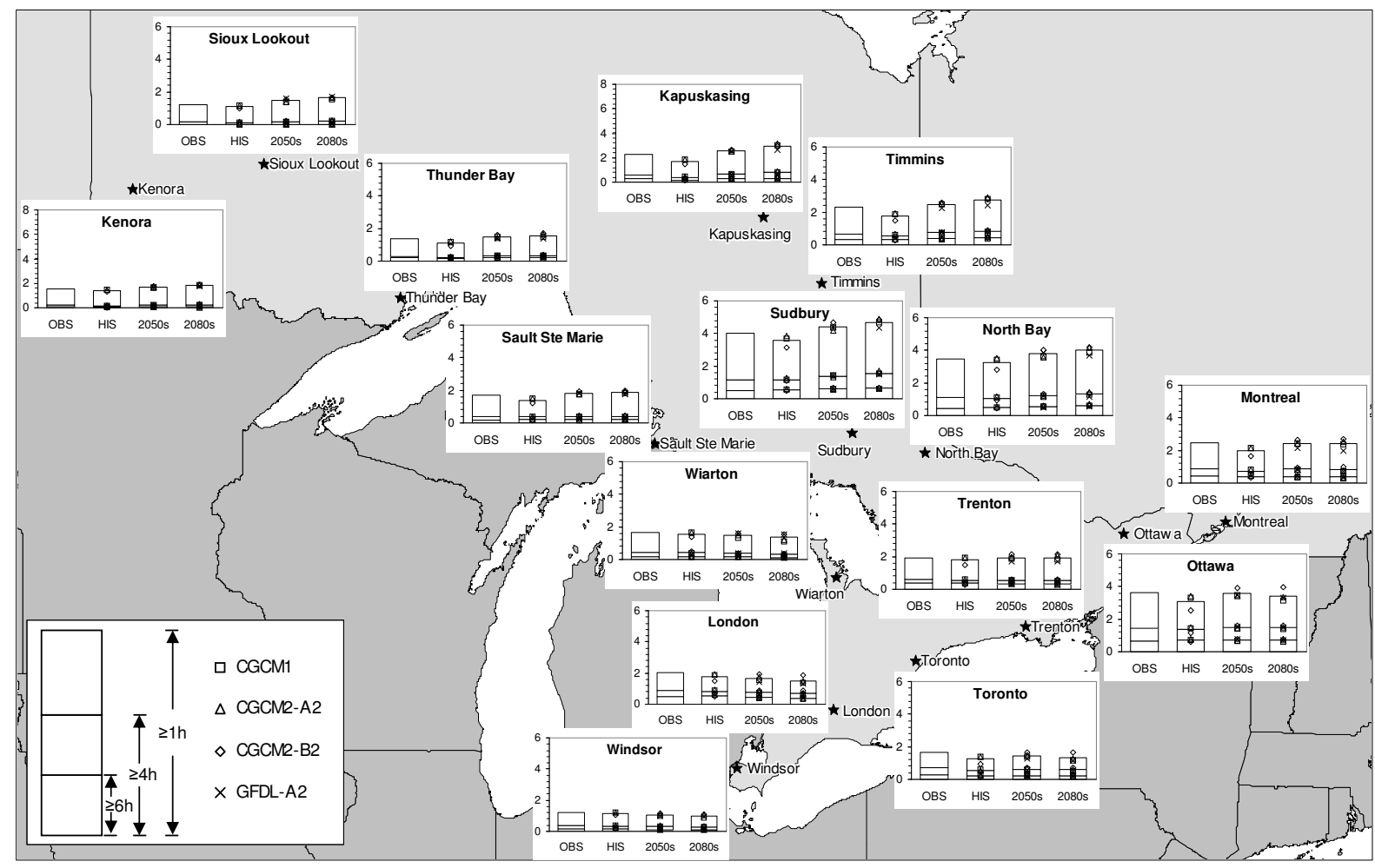

Fig. 6. Mean three-month total number of freezing rain events that occurred $\geq 1, \geq 4$, and $\geq 6 \mathrm{~h}$ during a day under the current climate during November, March and April 1961-2000 (the left two bars) and future time periods (2040-2069, 2070-2089) (the right two bars). OBS represents observation and HIS is CGCM historical runs.

runs. The corresponding numbers for two three-month periods (December-February and November, March and April) are shown in Figs. 5 and 6 (the two leftmost bars), respectively. Combining these two periods, the results indicate that, averaged across the study area, the mean annual number of freezing rain events (November-April) derived from CGCM historical runs was $0.67,0.24$ and 0.03 less than that derived from observations for freezing rain events lasting $\geq 1$, $\geq 4$, and $\geq 6 \mathrm{~h}$ during a day, respectively. The corresponding number of observed freezing rain events was 5.35, 1.66 and 0.80 days during November-April, 1958/59-2000/01. These small differences, resulting from GCM scenario and statistical downscaling biases, were considered to further adjust estimates of future freezing rain events.

To effectively compare the impacts of climate change on freezing rain for each three-month period, estimates of the occurrence frequency of future freezing rain events were analyzed for each individual month. The results showed that patterns of future freezing rain events were similar for each of the three colder months (i.e., December-February) and each of the three warmer months (i.e., November, March and April). As a result, the analysis was performed on each threemonth period. Estimates of the number of future freezing rain events for December-February are shown in Fig. 5. The model results show that, in the middle and late part of this century, the entire study area could experience more freezing rain events during this time period. As the results clearly indicate, the occurrence frequency of freezing rain events could increase when moving from the south to the north, and from the southwest to the northeast. For example, in Ottawa, averaging four GCM estimates, the results showed that the three-month total number of future freezing rain cases could increase from the past 40-year average level of 6.2, 2.6, and 1.5 days to $11.1,5.0$, and 3.3 days by the 2080 s, for freezing rain events with a duration $\geq 1,4$, and $6 \mathrm{~h}$ a day, respectively. The corresponding numbers for Windsor could increase from $3.9,1.0$, and 0.5 to $4.5,1.4$ and 0.8 .

The estimated total number of future freezing rain events for the warmer three-month period (November, March and April) is shown in Fig. 6. As it is immediately apparent from this figure, there are three distinctive patterns that emerge over the study area. The number of future freezing rain events, by the 2050s and 2080s, could: 1) Increase in the north of the study area (e.g., Kapuskasing, Sioux Lookout, Timmins); 2) Decrease in southern Ontario (e.g., Windsor, London, Toronto); and 3) Show little change in eastern Ontario (e.g., Ottawa, Trenton and Montreal, Quebec).

In addition to changes in the number of future freezing rain events, percentage changes in occurrence as compared to an annual average of the past 40 years are of considerable inter- 
Table 4. Average percentage changes in future freezing rain events of various durations for three regions of the study area, with a $95 \%$ confidence interval.

\begin{tabular}{|c|c|c|c|c|c|c|c|c|c|c|c|c|c|c|c|c|c|c|c|}
\hline \multicolumn{20}{|c|}{ December, January, February } \\
\hline \multirow{2}{*}{ Region $^{*}$} & \multirow[b]{2}{*}{ Duration } & \multicolumn{9}{|c|}{$2050 \mathrm{~S}$} & \multicolumn{9}{|c|}{$2080 \mathrm{~S}$} \\
\hline & & \multicolumn{3}{|c|}{$\begin{array}{c}\text { CGCM1 } \\
\text { CGCM2-A2 }\end{array}$} & \multicolumn{3}{|c|}{ CGCM2-B2 } & \multicolumn{3}{|c|}{ GFDL-A2 } & \multicolumn{3}{|c|}{$\begin{array}{c}\text { CGCM1 } \\
\text { CGCM2-A2 }\end{array}$} & \multicolumn{3}{|c|}{ CGCM2-B2 } & \multicolumn{3}{|c|}{ GFDL-A2 } \\
\hline \multirow{3}{*}{1} & $\geq 1 \mathrm{~h}$ & 91 & \pm & 22 & & \pm & 21 & 8 & \pm & & 168 & \pm & 34 & 77 & \pm & & 45 & \pm & 19 \\
\hline & $\geq 4 \mathrm{~h}$ & 118 & \pm & 34 & 87 & \pm & 35 & 38 & \pm & 66 & 196 & \pm & 40 & 89 & \pm & 28 & 84 & \pm & 100 \\
\hline & $\geq 6 \mathrm{~h}$ & 131 & \pm & 26 & & \pm & 39 & 39 & \pm & 40 & 216 & \pm & 43 & 92 & \pm & 20 & 88 & \pm & 39 \\
\hline \multirow{3}{*}{2} & $\geq 1 \mathrm{~h}$ & 70 & \pm & & 56 & \pm & 10 & 1 & \pm & 12 & 113 & \pm & 17 & 65 & \pm & 13 & 25 & \pm & 12 \\
\hline & $\geq 4 \mathrm{~h}$ & 84 & \pm & 13 & & \pm & 16 & 13 & \pm & 18 & 134 & \pm & 24 & 63 & \pm & 17 & 37 & \pm & 19 \\
\hline & $\geq 6 \mathrm{~h}$ & 99 & \pm & 15 & & \pm & 18 & 20 & \pm & 28 & 162 & \pm & 27 & 74 & \pm & 20 & 48 & \pm & 28 \\
\hline \multirow{3}{*}{3} & $\geq 1 \mathrm{~h}$ & 39 & \pm & 11 & 37 & \pm & 15 & 8 & \pm & 7 & 48 & \pm & 15 & 28 & \pm & 9 & 24 & \pm & 10 \\
\hline & $\geq 4 \mathrm{~h}$ & 51 & \pm & 18 & & \pm & 16 & 21 & \pm & 11 & 62 & \pm & 29 & 34 & \pm & 8 & 37 & \pm & 13 \\
\hline & $\geq 6 \mathrm{~h}$ & 57 & \pm & 27 & 57 & \pm & 20 & 23 & \pm & 23 & 71 & \pm & 44 & 38 & \pm & 10 & 39 & \pm & 29 \\
\hline \multicolumn{20}{|c|}{ November, March, April } \\
\hline \multirow{3}{*}{1} & $\geq 1 \mathrm{~h}$ & 11 & \pm & & 18 & $\perp$ & & 10 & \pm & 17 & 25 & \pm & 7 & 27 & \pm & 8 & 16 & \pm & 19 \\
\hline & $\geq 4 \mathrm{~h}$ & 11 & \pm & 4 & 20 & \pm & 7 & 11 & \pm & 8 & 30 & \pm & 11 & 34 & \pm & 7 & 12 & \pm & 10 \\
\hline & $\geq 6 \mathrm{~h}$ & 5 & \pm & 8 & & \pm & 14 & 7 & \pm & 27 & 11 & \pm & 20 & 32 & \pm & 15 & 6 & \pm & 31 \\
\hline \multirow{3}{*}{2} & $\geq 1 \mathrm{~h}$ & 0 & \pm & 4 & 12 & \pm & & -2 & \pm & 15 & 5 & \pm & 9 & 14 & \pm & 8 & -5 & \pm & 16 \\
\hline & $\geq 4 \mathrm{~h}$ & 2 & \pm & 8 & 14 & \pm & 10 & 4 & \pm & 17 & 7 & \pm & 17 & 18 & \pm & 15 & 0 & \pm & 23 \\
\hline & $\geq 6 \mathrm{~h}$ & 0 & \pm & 10 & 15 & \pm & 12 & 8 & \pm & 19 & 4 & \pm & 20 & 20 & \pm & 17 & 1 & \pm & 26 \\
\hline \multirow{3}{*}{3} & $\geq 1 \mathrm{~h}$ & -12 & \pm & 7 & & \pm & 10 & -13 & \pm & 19 & -19 & \pm & 11 & -2 & \pm & 13 & -17 & \pm & 21 \\
\hline & $\geq 4 \mathrm{~h}$ & -11 & \pm & 7 & & \pm & 14 & -13 & \pm & 14 & -18 & \pm & 11 & -2 & \pm & 17 & -17 & \pm & 19 \\
\hline & $\geq 6 \mathrm{~h}$ & -14 & \pm & 9 & -1 & \pm & 17 & -5 & \pm & 26 & -25 & \pm & 14 & -2 & \pm & 21 & -12 & \pm & 33 \\
\hline
\end{tabular}

\footnotetext{
* Region 1 is northern Ontario: Kapuskasing, Kenora, Sioux Lookout, Thunder Bay, and Timmins.

Region 2 is eastern Ontario: Montreal, Quebec, North Bay, Ottawa, Sudbury, and Trenton.

Region 3 is southern Ontario: London, Sault Ste. Marie, Toronto, Wiarton, and Windsor.
}

est to the public and decision makers. To calculate the range of changes in future freezing rain estimates among the GCMs and study area locations, the mean percentage changes with the $95 \%$ confidence interval $(95 \% \mathrm{CI})$ were evaluated for each of the three GCM scenarios within each of the three regions (Table 4). The study area was divided into three regions based on the magnitude of percentage change in the projection of future freezing rain events for both three-month periods. Region 1 is northern Ontario, including Kapuskasing, Kenora, Sioux Lookout, Thunder Bay, and Timmins, where the greatest percentage increase is projected to occur. Region 2 is eastern Ontario, including North Bay, Ottawa, Sudbury, Trenton, and Montreal, Quebec, where a smaller percentage increase in future freezing rain events is projected as compared to Region 1. Region 3 is southern Ontario, including London, Sault Ste Marie, Toronto, Wiarton, and Windsor, which is estimated to experience the smallest percentage increase in future freezing rain events. The regions defined here are not standard for Environment Canada's forecast regions. In addition, the results derived from the GCM scenarios were grouped together to calculate mean future freezing rain percentage changes based on similarities and differences between the scenarios in terms of greenhouse gas forcing (refer to Sect. 2 for details). Two scenarios - CGCM1 and CGCM2-A2 - were combined since both used similar greenhouse gas forcing; percentage changes in future freezing rain events derived from both scenarios are similar. The results derived from CGCM2-B2 were kept separate as the greenhouse gas forcing used in this scenario is quite different from that used by the other two. The results derived from GFDLA2 were also kept separate since its historical run was not available to correct the model bias.

Average percentage changes with the $95 \% \mathrm{CI}$ in future freezing rain events for these three regions of the study area are shown in Table 4. The major results are summarized as follows:

1. Percentage increases in future freezing rain events for three-month colder period derived from CGCM1 and CGCM2-A2 are usually greater than those derived from CGCM2-B2; the B2 scenario is associated with less future warming, especially in the second half of the 21 st century. Averaging all freezing rain events $(\geq 1$, $\geq 4, \geq 6 \mathrm{~h}$ ) across the study area, the increase derived from CGCM1/CGCM2-A2 is $25 \%$ higher by the 2050 s and $100 \%$ higher by the 2080 s than that derived from CGCM2-A2. The increases derived from GFDL-A2 are the lowest among the scenarios used in the study; one reason might be that the historical run was not available to correct the model bias.

2. The magnitude of percentage increases in future freezing rain events for the three colder months is generally greater in the north than in the south. Averaging the four GCM scenarios and freezing rain events over the three 


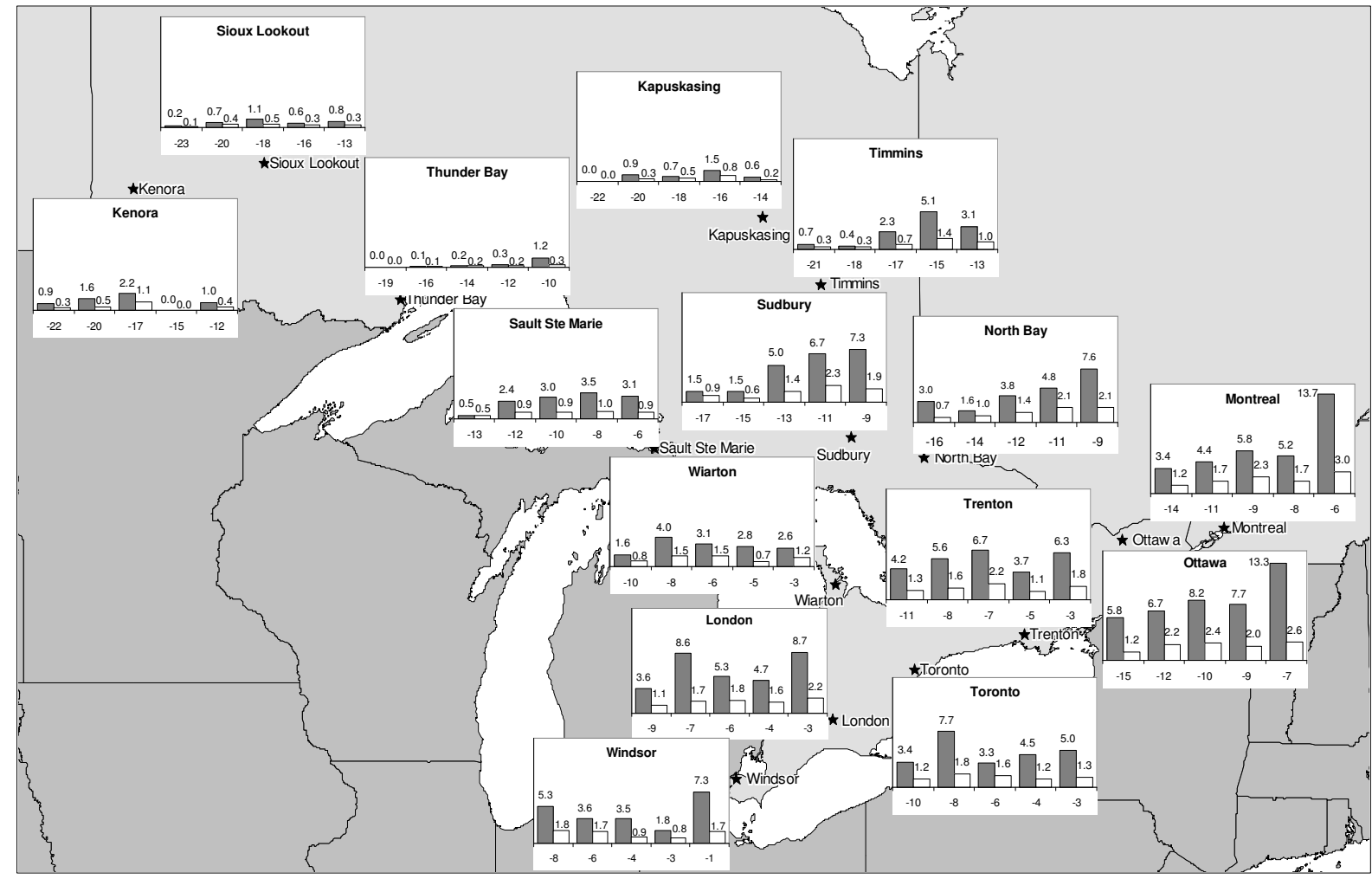

Fig. 7. Monthly mean total hours (grey bar) and days (white bar) of freezing rain events within each of the monthly mean temperature quintiles in January, 1959-2001 (the horizontal axis is within-quintile monthly mean temperature).

time durations, Regions 1, 2, and 3 could experience about $85 \%$ (95\% CI: $\pm 13 \%$ ), $60 \%$ (95\% CI: $\pm 9 \%$ ), and $40 \%$ (95\% CI: $\pm 6 \%$ ) more freezing rain events, respectively, by the 2050s as compared to the average occurrence over the past 40 years. Corresponding increases by the 2080 s could be about $135 \%$ (95\% CI: $\pm 20 \%$ ), 95\% (95\% CI: $\pm 13 \%$ ), and $45 \%$ (95\% CI: $\pm 9 \%$ ).

3. The magnitude of percentage increases in future freezing rain events for the three colder months is generally greater for a longer duration event than for a shorter duration event. Averaging the four GCM scenarios across the study area, freezing rain events lasting $\geq 1, \geq 4$, and $\geq 6$ hours a day could, compared to present levels, increase about $50 \%$ (95\% CI: $\pm 9 \%$ ), $65 \%$ (95\% CI: $\pm 11 \%$ ), and $70 \%$ (95\% CI: $\pm 11 \%$ ), respectively, by the 2050s. Corresponding increases by the 2080s are projected to be about $75 \%$ (95\% CI: $\pm 14 \%$ ), $95 \%$ (95\% CI: $\pm 17 \%$ ), and $100 \%$ (95\% CI: $\pm 19 \%$ ).

4. Percentage changes in future freezing rain events for the three warmer months could be much smaller than for the three colder months. Averaging both the four GCM scenarios and three duration freezing rain events, Region 1 could experience about $10 \%$ (95\% CI: $\pm 2 \%$ ) and $20 \%$ (95\% CI: $\pm 4 \%$ ) more freezing rain events by the 2050s and 2080s, respectively. In Region 3, future freezing rain events could decrease about $10 \%$ (95\% CI: $\pm 3 \%$ ) and $15 \%$ (95\% CI: $\pm 5 \%$ ) by the 2050 s and 2080s, respectively. In Region 2, future freezing rain events are projected to occur with similar frequency as at the present time.

\section{Discussion}

As described above, the occurrence frequency of future freezing rain events in the three colder months (DecemberFebruary) could increase over south-central Canada. One possible reason is that, as temperatures warm under future climate scenarios, the boundary between snowfall and rainfall in the study area is likely to move towards the north or northeast. Another possible reason is that in the sites located in southern Ontario, freezing rain occurrences may be tempered by the influence of the Great Lakes (Klaassen et al., 2003). On the other hand, in the three warmer months (November, March and April), as temperatures warm, future freezing rain is likely to occur less frequently than at the present time. One reason for this may be that some precipitation falling as freezing rain under the current climate could fall as liquid rain under future warmer climate scenarios.

To test this theory, monthly mean temperature and monthly total occurrence frequency of freezing rain hours and days were analyzed for each month. Monthly mean tem- 


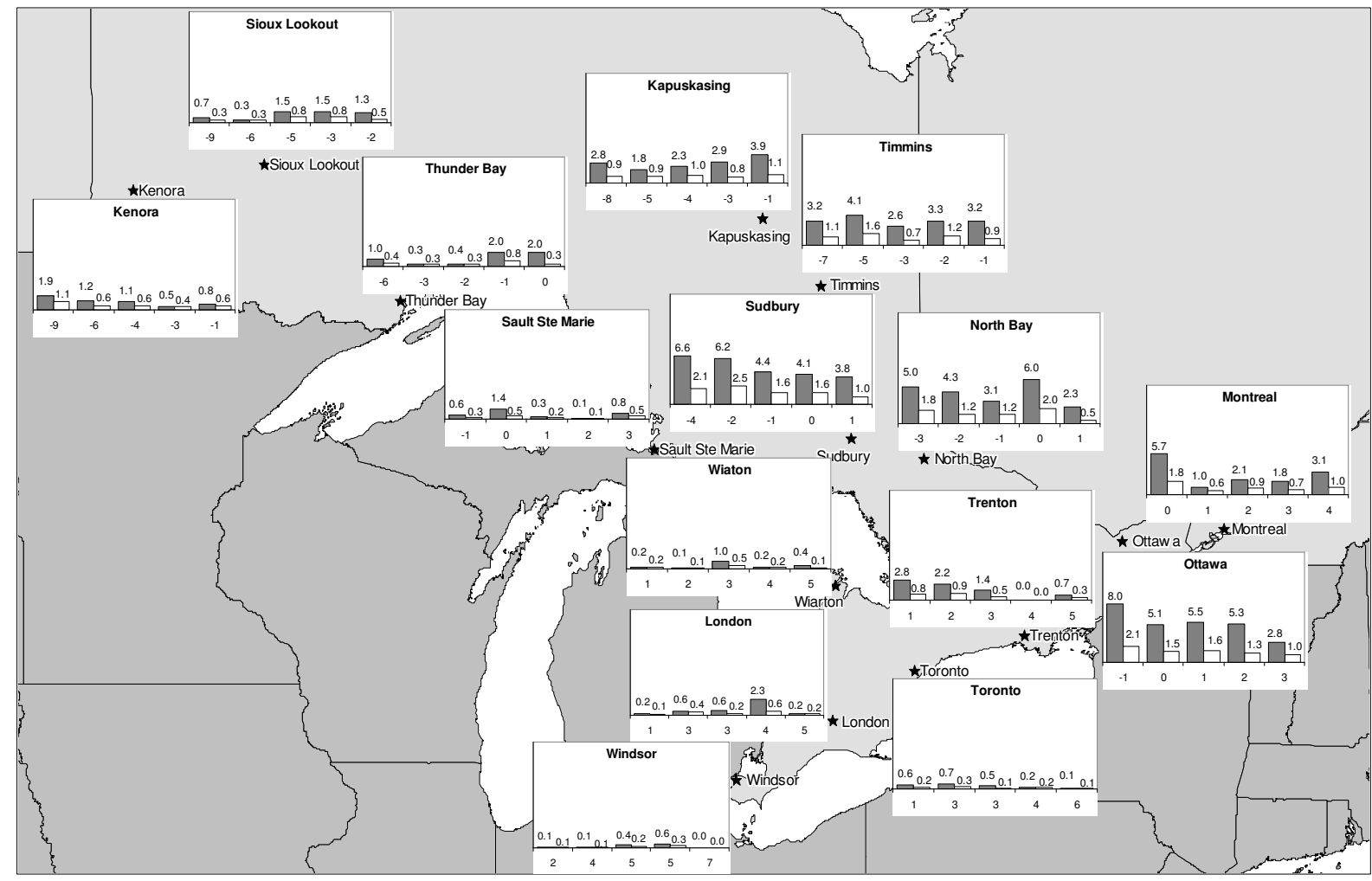

Fig. 8. Monthly mean total hours (grey bar) and days (white bar) of freezing rain events within each of the monthly mean temperature quintiles in November, 1958-2000 (the horizontal axis is within-quintile monthly mean temperature).

peratures were sorted in descending order during the period 1958-2001 for each of the selected stations. The months were then divided into temperature quintiles based on the sorted monthly mean temperatures. Mean frequencies of freezing rain occurrence for each of the quintiles and the quintile mean temperatures were calculated. The first quintile represents the highest monthly mean temperature, the second quintile the second highest, and so on, with the fifth quintile representing the lowest monthly mean temperature.

The results of the quintile analysis are provided in Fig. 7 for January as an example (similar results were found for December and February but not shown here due to limitations of space,). On average in January the monthly total frequency of freezing rain events in the northern area, especially in Montreal, Ottawa, North Bay, Sault Ste Marie, and Sudbury, increases from the lowest to the highest temperature quintiles. For example, in Ottawa, as the withinquintile monthly mean temperature increases from -15 to -10 to $-7^{\circ} \mathrm{C}$, the monthly total hours of freezing rain occurrence increase from 5.8 to 8.2 to 13.3 . Similarly, the monthly total number of days with freezing rain events increases from 1.2 to 2.4 to 2.8 . The average number of hours per day, when freezing rain is observed, is not affected by an increase in temperature. Colder monthly temperatures in this area likely indicate a significant number of days within the month when Arctic high pressure dominated and synop- tic storms moved well south of the area. However, in the south, especially in Windsor, Wiarton, and London, with the exception of the individual quintile, the opposite relationship between monthly temperatures and freezing rain occurrences generally appears.

For the three warmer months (i.e., November, March and April), the relationship between monthly total frequency of freezing rain events and monthly mean temperatures is usually opposite to that for the three colder months. The results of the quintile analysis for November are shown in Fig. 8, as an example; similar results were found for March and April. As can be seen from Fig. 8, on average in November, the monthly total frequency of freezing rain events generally decreases from the lowest to highest temperature quintiles for the entire study area, except for some of the most northern stations (i.e., Kapuskasing, Sioux Lookout, and Thunder Bay). For example, in Ottawa, as the within-quintile monthly mean temperature in November increases from -1 to 1 to $3^{\circ} \mathrm{C}$, the monthly total hours of freezing rain occurrence decrease from 8.0 to 5.5 to 2.8 . Similarly, the monthly total number of days with freezing rain events decreases from 2.1 to 1.6 to 1.0 . In the late autumn and early spring, over the study area, freezing rain will likely occur when temperatures are low enough; otherwise, precipitation will fall as the liquid phase. 
As analyzed above, since the monthly total frequency of freezing rain events is generally associated with withinquintile monthly mean temperatures, this quintile analysis might be used to estimate changes in future freezing rain events. One question could be asked: Can the results derived from synoptic weather typing be similarly obtained using the monthly mean temperature quintile analysis? To answer this question, monthly mean temperature using downscaled climate change scenarios for two future time periods (20402059 and 2070-2089) was examined. Monthly mean temperatures for almost all future months, no matter which scenario was used, fell into the warmest monthly mean temperature quintile calculated from historical observations. Consequently, if the monthly mean temperature quintile analysis is used to estimate changes in the occurrence frequency of future freezing rain events, the resulting frequency will not change from one scenario to another nor over time. As a result, the monthly mean temperature quintile analysis is not suitable to use for estimating changes in future freezing rain events since it considers only monthly mean temperature associated with monthly total freezing rain cases.

The complex physical process of freezing rain formation is another reason why the monthly mean temperature quintile is not suitable to use for estimating changes in future freezing rain events. Freezing rain can only be formed under certain weather conditions; surface thermal conditions and vertical temperatures must be within a certain range, such as an above-freezing layer in the atmosphere and a belowfreezing layer near and at the surface (Klaassen et al., 2003; Cheng et al., 2004). Synoptic weather typing takes into account such critical weather information, including a suite of other weather elements with hourly time resolutions and four-hourly vertical profiles. As a result, it can be concluded that synoptic weather typing could be used to estimate the occurrence frequency of future freezing rain cases. The historical relationships between temperature and freezing rain events derived from the monthly mean temperature quintile provide evidence that climate change will have an impact on these events.

\section{Conclusions}

The overarching purpose of the study was to assess possible changes in future freezing rain events in south-central Canada, based on historical relationships between weather types and freezing rain events as well as downscaled future climate scenarios. This study aims to provide decision makers with scientific information needed to improve the adaptive capacity of the infrastructure at risk of being impacted by freezing rain in south-central Canada due to climate change. The results of the study are intended to contribute to the Ontario Emergency Management and Civil Protection Act under Bill 148, which attempts to reduce risks of disasters by requiring that every municipality and provincial ministry de- velop an emergency management plan (Ontario Management Act, 2002; Auld et al., 2004). This study is also intended to help municipalities anticipate the possible increase in future freezing rain events and mitigate the long-term risks to people, communities, and properties from the effects of a changing climate. The major findings from assessments of future freezing rain events were described briefly as follows:

A general conclusion that could be made from this study is that synoptic weather typing could be used to estimate the occurrence frequency of future freezing rain cases. As temperatures warm under future climate scenarios, the model results indicate that the entire study area could experience more freezing rain events during the winter season (DecemberFebruary). The results clearly show that a continuing increase in the magnitude of freezing rain events moving across the study area from the south to the north and from the southwest to the northeast. On average, across the study area, freezing rain events for the three colder months (DecemberFebruary) could increase $40-85 \%$ (95\% CI: $\pm 6 \%- \pm 13 \%$ ) by the 2050 s and $45-135 \%$ (95\% CI: $\pm 9 \%- \pm 20 \%$ ) by the 2080s. For the three warmer months (November, March and April), percentage changes in future freezing rain events could be much smaller. On average, northern Ontario could experience about $10 \%$ (95\% CI: $\pm 2 \%$ ) and $20 \%$ (95\% CI: $\pm 4 \%$ ) more freezing rain events by the 2050 s and 2080 s, respectively. However, future freezing rain events in southern Ontario could decrease about $10 \%$ (95\% CI: $\pm 3 \%$ ) and $15 \%$ (95\% CI: $\pm 5 \%$ ) by the 2050 s and 2080 s, respectively. In eastern Ontario (including Montreal, Quebec), future freezing rain events are projected to occur at a similar frequency as they do currently.

There is, of course, some degree of uncertainty in the assessment of future freezing rain events, although considerable effort was made in this study to transfer GCM-scale scenarios to station-scale information using statistical downscaling transfer functions. Through the downscaling process, the GCM model bias was removed using the past 40-year historical relationships between regional-scale predictors and station-scale weather elements. As a result, following downscaling, the quality of climate change scenarios was much improved. For example, data distribution of the downscaled GCM historical runs was similar to that of the observations during the same time period. In addition, small differences in occurrence frequency between downscaled historical runs and observations were considered to further correct future freezing rain assessments. Such corrections could not be applied to the GFDL output since the model historical run was not available. Therefore, the rate of change of future freezing rain events derived from the GFDL scenario is usually smaller than that derived from CGCM scenarios across the study area, and consequently yields a higher degree of uncertainty. Although some degree of uncertainty remains in the assessment of change in future freezing rain events, the results for the three colder months (December-February) derived from all GCM scenarios used in the study showed a 
pattern of consistent increase across the study area. This suggests that south-central Canada could experience more freezing rain events in the middle and late part of this century.

Acknowledgements. This research was funded in part by the Canadian Federal Program of Energy Research and Development (PERD). The authors are grateful for the suggestions made by two anonymous reviewers, which greatly improved the original manuscript.

Edited by: M.-C. Llasat

Reviewed by: two referees

\section{References}

Allen, R. L. and Erickson, M. C.: AVN-based MOS precipitation type guidance for the United States, NWS Technical Procedures Bulletin No. 476, NOAA, U.S. Dept. of Commerce, 2001.

Allison, P. D.: Logistic Regression Using the SAS System: Theory and Application, Cary, NC, SAS Institute Inc., 1999.

Antolik, M. S.: An overview of the National Weather Service's centralized statistical quantitative precipitation forecasts, J. Hydrol., 239, 306-337, 2000.

Auld, H., MacIver, D., Klaassen, J., Comer, N., and Tugwood, B.: Atmospheric Hazards in Ontario, ACSD Science Assessment Series No. 3 Meteorological Service of Canada, Toronto, Environment Canada, 2004.

Bárdossy, A.: Downscaling from GCMs to local climate through stochastic linkages, in: Climate Change, Uncertainty and Decision-Making, edited by: Paoli, G., NERAM, Waterloo, ON, 33-46, 1994.

Bass, B. and Brook, J. R.: Downscaling procedures as a tool for integration of multiple air issues, Environ. Monit. Assess., 46, 151-174, 1997.

Bernstein, B. C.: Regional and local influences on freezing drizzle, freezing rain, and ice pellet events, Wea. Forecast., 15, 485-507, 2000.

Berry Jr., F. A., Bollay, E., and Beers, N. R. (Eds.): Handbook of Meteorology, New York: McGraw-Hill, 1945.

Bocchieri, J. R.: The objective use of upper air soundings to specify precipitation type, Mon. Wea. Rev., 108, 596-603, 1980.

Bourgouin, P.: A method to determine precipitation types, Wea. Forecast., 15, 583-592, 2000.

Boyce, A. J.: Mapping diversity: a comparative study of some numerical methods, in: Numerical Taxonomy, edited by: Cole, A. J., Academic Press, New York, 1-31, 1996.

Bürger, G.: Expanded downscaling for generating local weather scenarios, Clim. Res., 7, 111-128, 1996.

Carbone, G. J. and Bramante, P. D.: Translating monthly temperature from regional to local scale in the southeastern United States, Clim. Res., 5, 229-242, 1995.

Carrière, J. M., Lainard, C., Le Bot, C., and Robart, F.: A climatological study of surface freezing precipitation in Europe, Meteorol. Appl., 7, 220-238, 2000.

Carter, G. M., Dallavalle, J. P., and Glahn, H. R.: Statistical forecasts based on the National Meteorological Center's numerical weather prediction system, Weat. Forecast., 4, 401-412, 1989.

Cheng, C. S., Auld, H., Li, G., Klaassen, J., Tugwood, B., and Li, Q.: An automated synoptic typing procedure to predict freezing rain: An application to Ottawa, Ontario, Wea. Forecast., 19, 751768, 2004.

Cheng, S. and Lam, K. C.: Synoptic typing and its application to the assessment of climatic impact on concentrations of sulfur dioxide and nitrogen oxides in Hong Kong, Atmos. Environ., 34, 585594, 2000.

Cortinas Jr., J. V.: A climatology of freezing rain in the Great Lakes Region of North America, Mon. Wea. Rev., 128, 3574-3588, 2000.

Cortinas Jr., J. V., Brill, K. F., Baldwin, M. E.: Probabilistic forecasts of precipitation type, Preprints, 16th Conf. on Probability and Statistics in the Atmospheric Sciences, Orlando, FL, AMS, 140-145, 2002.

Cortinas Jr., J. V., Bernstein, B. C., Robbins, C. C., and Strapp, J. W.: An analysis of freezing rain, freezing drizzle, and ice pellets across the United States and Canada: 1976-90, Wea. Forecast., 19, 377-390, 2004.

Czys, R. R., Scott, R. W., Tang, K. C., Przybylinski, R. W., and Sabones, M. E.: A physical based, nondimensional parameter for discriminating between locations of freezing rain and ice pellets, Wea. Forecast., 11, 591-597, 1996.

Davis, J. C.: Statistics and Data Analysis in Geology, 2nd Edition, New York, NY, John Wiley \& Sons., 1986.

DeGaetano, A.: Delineation of mesoscale climate zones in the northeastern United States using a novel approach to cluster analysis, J Clim., 9, 1765-1782, 1996.

Delworth, T. L., Stouffer, R. J., Dixon, K. W., Spelman, M. J., Knutson, T. R., Broccoli, A. J., Kushner, P. J., and Wetherald, R. T. Review of simulations of climate variability and change with the GFDL R30 coupled climate model, Clim. Dynam., 19, 555-574, 2002.

Dettinger, M. D., Cayan, D. R., Meyer, M. K., and Jeton, A. E.: Simulated hydrologic responses to climate variations and change in the Merced, Carson, and American River Basins, Sierra Nevada, California, 1900-2099, Clim. Change, 62, 283317, 2004.

Dore, M. H. I.: Forecasting the conditional probabilities of natural disasters in Canada as a guide for disaster preparedness, Nat. Hazards, 28, 249-269, 2003.

Environment Canada: Ice Storm'98 - The Meteorological Event, Technical Report, Environment Canada - Ontario Region, 1998.

Environment Canada: CGCM RUNS FORCING: Equivalent $\mathrm{CO}_{2}$ concentrations used in CCCma coupled global climate model simulations, http://www.cccma.bc.ec.gc.ca/data/ cgcm/cgcm_forcing.shtml, accessed November 2005.

Forbes, G. S., Anthes, R. A., Thomson, D. W.: Synoptic and mesoscale aspects of an Appalachian ice storm associated with cold-air damming, Mon. Wea. Rev., 115, 564-591, 1987.

Gay, D. A. and Davis, R. E.: Freezing rain and sleet climatology of the southeastern USA, Clim. Res., 3, 209-220, 1993.

Glahn, H. R. and Lowry, D. A.: The use of model output statistics (MOS) in objective weather forecasting, J. Appl. Meteorol., 11, 1203-1211, 1972.

Grotch, S. L. and MacCracken, M. C.: The use of general circulation models to predict regional climatic change, J. Clim., 4 , 286-303, 1991.

Hayhoe, K., Cayanc, D., Field, C. B., Frumhoff, P. C., Maurer, E. P., Miller, N. L., Moser, S. C., Schneider, S. H., Cahill, K. N., Cleland, E. E., Dale, L., Drapek, R., Hanemann, M.R., Kalkstein, 
L. S., Lenihan, J., Lunch, C. K., Neilson, R. P., Sheridan, S. C., and Verville, J. H.: Emissions pathways, climate change, and impacts on California, Proceedings of the National Academy of Sciences of the United States of America, 101, 12 422-12 427, 2004.

Hewitson, B. C. and Crane, R. G.: Large-scale atmospheric controls on local precipitation in Tropical Mexico, Geophys. Res. Lett., 19, 1835-1838, 1992.

Hewitson, B. C. and Crane, R. G.: Climate downscaling: Techniques and application, Clim. Res., 7, 13-26, 1996.

Higuchi, K., Yuen, C. W., and Shabbar, A.: Ice Storm '98 in southcentral Canada and northeastern United States: A climatological perspective, Theor. Appl. Climatol., 66, 61-79, 2000.

Huffman, G. J. and Norman Jr., G. A.: The supercooled warm rain process and the specification of freezing precipitation, Mon. .Wea. Rev., 116, 2172-2182, 1988.

Huth, R.: Statistical downscaling in central Europe: Evaluation of methods and potential predictors, Clim. Res., 13, 91-101, 1999.

Huth, R., Nemešová, I., and Klimperová, N.: Weather categorization based on the average linkage clustering technique: An application to European mid-latitudes, Int. J. Climatol., 13, 817-835, 1993.

Jones, K. F. and Mulherin, N. D.: An evaluation of the severity of the January 1998 ice storm in Northern New England, Report for Federal Emergency Management Agency Region 1, Cold Regions Research and Engineering Laboratory, 1998.

Kalkstein, L. S. and Corrigan, P.: A synoptic climatological approach for geographical analysis: Assessment of sulfur dioxide concentrations, Ann. Assoc. Amer. Geographers, 76, 381-395, 1986.

Keeter, K. K. and Cline, J. W.: The objective use of observed and forecast thickness values to predict precipitation type in North Carolina, Wea. Forecast., 6, 456-469, 1991.

Kettle, H. and Thompson, R.: Statistical downscaling in European mountains: Verification of reconstructed air temperature, Clim. Res., 26, 97-112, 2004.

Kim, J. W., Chang, J. T., Baker, N. L., Wilks, D. S., and Gates, W. L.: The statistical problem of climate inversion: Determination of the relationship between local and large-scale climate, Mon. Wea. Rev., 112, 2069-2077, 1984.

Klaassen, J., Cheng, S. C., Auld, H., Li, Q., Ros, E., Geast, M., $\mathrm{Li}, \mathrm{G}$, and Lee, R.: Estimation of severe ice storms risks for south-central Canada. Technical Report, the Office of Critical Infrastructure Protection and Emergency Preparedness (OCIPEP), Canada, 2003.

Konrad, C. E. II.: An empirical approach for delineating fine scaled spatial patterns of freezing rain in the Appalachian region of the USA, Clim. Res., 10, 217-227, 1998.

Milton, J. and Bourque, A.: A climatological account of the January 1998 ice storm in Quebec, Scientific Report, Atmospheric Sciences and Environmental Issues Division, Environment Canada, Quebec Region, 1999.

Ontario Management Act: Legislative Assembly of Ontario: Bill 148 2002: An Act to provide for declarations of death in certain circumstances and to amend the Emergency Plans Act, http://www.ontla.on.ca/documents/Bills/37_ Parliament/Session3/b148ra_e.htm, (accessed June 2006).

Penlap, E. K., Matulla, C., von Storch, H., and Kamga, F. M.: Downscaling of GCM scenarios to assess precipitation changes in the little rainy season (March-June) in Cameroon, Clim. Res., 26, 85-96, 2004.

Rauber, R. M., Ramamurthy, M. K., and Tokay, A.: Synoptic and mesoscale structure of a severe freezing rain event: The St. Valentine's Day ice storm, Wea. Forecast., 9, 183-208, 1994.

Rauber, R. M., Olthoff, L. S., and Ramamurthy, M. K.: The relative importance of warm rain and melting processes in freezing precipitation events, J. Appl. Meteor., 39, 1185-1195, 2000.

Rauber, R. M., Olthoff, L. S., Ramamurthy, M. K., Miller, D., and Kunkel, K. E.: A synoptic weather pattern and sounding-based climatology of freezing precipitation in the United States East of the Rocky Mountains, J. Appl. Meteorol., 40, 1724-1747, 2001.

Regan, M.: Canadian ice storm 1998, WMO Bull., 47, 250-256, 1998.

Robbins, C. C. and Cortinas Jr., J. V.: Local and synoptic environments associated with freezing rain in the contiguous United States, Wea. Forecast., 17, 47-65, 2002.

SAS Institute Inc.: SAS/STAT User's Guide, Version 8, 1999.

Schubert, S. and Henderson-Sellers, A.: A statistical model to downscale local daily temperature extremes from synoptic-scale atmospheric circulation patterns in the Australian region, Clim. Dyn., 13, 223-234, 1997.

Shen, S. S. P., Dzikowski , P., Li, G., and Griffith, D.: Interpolation of 1961-97 daily temperature and precipitation data onto Alberta polygons of ecodistrict and soil landscapes of Canada, J. Appl. Meteorol., 40, 2162-2177, 2001.

Stewart, R. E. and King, P.: Freezing precipitation in winter storms, Mon. Wea. Rev., 115, 1270-1279, 1987.

Strapp, J. W., Stuart, R. A., and Isaac, G. A.: A Canadian climatology of freezing precipitation, and a detailed study using data from St. John's, Newfoundland, Proceedings of FAA International Conference on Aircraft In-flight Icing, Springfield, Virginia, 6-8 May 1996, 45-56, 1996.

Stuart, R. A. and Isaac, G. A.: Freezing precipitation in Canada, Atmosphere-Ocean, 37, 87-102, 1999.

Vallée, M. and Wilson, L. J.: Updateable model output statistics: An effective tool for evaluation of NWP forecasts, Proceedings of the 19th Conference on Weather Analysis and Forecasting, San Antonio, Texas, 12-16 August 2002, American Meteorological Society, 97-100, 2002.

Vislocky, R. L. and Fritsch, J. M.: Improved Model Output Statistics forecasts through model consensus, Bull. Amer. Meteorol. Soc., 76, 1157-1164, 1995.

von Storch, H., Zorita, E., and Cubasch, U.: Downscaling of global climate change estimates to regional scales: An application to Iberian rainfall in wintertime, J. Clim., 6, 1161-1171, 1993.

Wagner, J. A.: Mean temperature from $1000 \mathrm{MB}$ to $500 \mathrm{MB}$ as a predictor of precipitation type, Bull. Amer. Meteorol. Soc., 38, 584-590, 1957.

Wigley, T. M. L., Jones, P. D., Briffa, K. R., and Smith, G.: Obtaining sub-grid-scale information from coarse-resolution general circulation model output, J. Geophy. Res., 95, 1943-1953, 1990.

Wilby, R. L., Dawson, C. W., and Barrow, E. M.: SDSM: A decision support tool for the assessment of regional climate change impacts, Environ. Modell. Software, 17, 147-159, 2002.

Wilby, R. L. and Wigley, T. M. L.: Downscaling general circulation model output: A review of methods and limitations, Prog. Phys. Geogr., 21, 530-548, 1997. 